\title{
INTEGRAÇÃO NÃO-FORMAL DE MIGRANTES E REFUGIADOS EM PORTUGAL - PROJETO INTEGRARARTE
}

\author{
NON-FORMAL INTEGRATION OF MIGRANTS AND REFUGEES IN PORTUGAL - PROJETO INTEGRARARTE \\ INTEGRACIÓN NO FORMAL DE MIGRANTES Y REFUGIADOS EN PORTUGAL - PROJETO INTEGRARARTE
}

\author{
FARIA, Maria João 1 \\ OLIVEIRA, Clara Costa ${ }^{2}$
}

\begin{abstract}
RESUMO
O estado português assegura aos refugiados o acesso ao subsistema escolar e ao Serviço Nacional de Saúde (SNS), sendo quase omissos projetos de médio-longo prazos na esfera não formal e informal. A pesquisa ocorreu com duas famílias refugiadas e a metodologia adotada foi a de investigação-ação. Semanalmente se realizaram várias atividades agrupadas em ateliers que se focaram, mas não exclusivo, na arte, tendo em conta os Objetivos de Desenvolvimento Sustentável para 2030 da ONU (ODS), e os do Ano Europeu do Patrimônio Cultural 2018 (AEPC). Revelou-se uma poderosa ferramenta que estimulou a capacidade de exteriorizar as mais diversas emoções, sentimentos e pensamentos de uma forma bela e simples.
\end{abstract}

Palavras-chave: Integração. Não-Formal. Refugiados. Migrantes. Portugal.

\section{ABSTRACT}

The Portuguese State guarantees refugees access to the school subsystem and to the National Health Service (SNS), with almost silent projects in the medium-long term in the non-formal and informal sphere. The research was carried out with two refugee families and the methodology adopted was action-research method. On a weekly basis, several activities into workshops were carried out that focused, not exclusively, on art, taking into account the United Nations Sustainable Development Goals for 2030, and those of the 2018 European Year of Cultural Heritage. It turned out to be a powerful tool that stimulated the ability to express the most diverse emotions, feelings and thoughts in a beautiful and simple way.

Keywords: Integration. Non-Formal. Refugees. Migrants. Portugal.

\section{RESUMEN}

El Estado portugués garantiza a los refugiados el acceso al subsistema escolar y al Servicio Nacional de Salud (SNS), con proyectos casi silenciosos a medio-largo plazo en el ámbito no formal e informal. La investigación se llevó a cabo con dos familias de refugiados y la metodología adoptada fue la de investigación-acción. Semanalmente, se realizaron varias actividades agrupadas en talleres que se enfocaron, no exclusivamente, en el arte, teniendo en cuenta los Objetivos de Desarrollo Sostenible de Naciones Unidas para 2030 (ODS), y los del Año Europeo del Patrimonio Cultural 2018 (AEPC). Resultó ser una herramienta poderosa que estimuló la capacidad de exteriorizar las más diversas emociones, sentimientos y pensamientos de una manera hermosa y sencilla.

Palabras clave: Integración. No-Formal. Refugiados Migrantes. Portugal.

\footnotetext{
${ }^{1}$ Universidade do Minho - UMINHO-Braga/Guimarães - Portugal.

${ }^{2}$ Universidade do Minho - UMINHO-Braga/Guimarães - Portugal.

Desde 2014 que uma das autoras se encontra no terreno, quer como voluntária informal, quer como mentora voluntária de várias instituições dirigidas para migrantes e refugiados, em Portugal. Enquanto académica, supervisionou teses de mestrado de investigação-ação com população refugiada (sob alçada de organismos administrativos portugueses, quer da PAR - Plataforma de Apoio aos refugiados, de responsabilidade directa de fundos da Comunidade Europeia, da qual Portugal é membro - quer da Segurança Social- CTR). O trabalho agora apresentado foi elaborado no âmbito da segunda instituição. A outra autora tornou-se a primeira mestre em educação não formal de refugiados em Portugal, com este projeto.
} 


\section{INTRODUÇÃO}

A escrita deste texto tem por base a assunção da dimensão subjetiva dos investigadores pelas autoras, dado tratar-se de um projeto de investigação-ação (ANDER-EGG, 2002; GUERRA, 2000), implicando a co-construção de mundos gerados em acopulamentos estruturais (OLIVEIRA, 1999), promovendo-se uma educação permamente e comunitária de todos os envolvidos (UNESCO, 1976; OLIVEIRA, 2009), nós incluídas. Este texto tem por base a tese de mestrado aprovada em $2018^{3}$.

Foi uma intervenção de tempo médio (nove meses) com duas famílias, uma congolesa e uma de nacionalidade mista (ucraniana-bangladeshiana, e portuguesa - com criança nascida em Portugal durante o período do projeto). A integração destas famílias, no momento de redação deste artigo, continua a ocorrer de um modo regular com uma delas; a outra considera-se suficientemente integrada, não tendo sido por ela contactadas. Assim, após a defesa da tese de mestrado em questão, a supervisora garante suporte na integração dessas famílias, desde que por elas solicitado; a mestre continua também a dar suporte, como voluntária, à família, ao nível da leitura e escrita do português.

Este trabalho analisou estudos desenvolvidos sobre as formas de acolhimento, cuidado e aprendizagem na experiência de refugiados em ambientes de educação não formal, enquadradas nos Objetivos de Desenvolvimento Sustentável (ODS), com especial incidência em alguns deles, que passamos a enunciar e que serão convocados na discussão de dados deste artigo, aqui identificados: Objetivo 4: Garantir o acesso à educação inclusiva, de qualidade e equitativa, e promover oportunidades de aprendizagem ao longo da vida para todos". Objetivo 5: Alcançar a igualdade de género e empoderar todas as mulheres".

\section{ENQUADRAMENTO TEÓRICO}

Segundo Canário (2000), o conceito de educação permanente ou educação ao longo da vida emergiu no início dos anos 70, numa conjuntura de rutura e de crítica com o modelo escolar dos anos 60. Ela vincula-se à educação integral de uma pessoa, desde que nasce até à sua morte, e podemos enquadrá-la nos 4 pilares da educação (não esquecendo que a escola e a educação formal são apenas um subsistema), enunciados pela UNESCO (1976), apelando à realização completa do Homem, em toda a sua riqueza e na complexidade das suas manifestações e dos seus compromissos: indivíduo ou cidadão, membro de uma família ou até mesmo inventor de técnicas e criador de sonhos. Tudo isto nos surge irrealizável se não focados em «aprender a ser», reforçadora de todas as dimensões humanas, quer na aprendizagem, quer na educação.

O conceito de educação de adultos possui carácter polissémico, multifacetado e complexo de definir. Barros (2013) reconhece que a par da diversidade conceptual, a literatura de especialidade encerra confusões epistemológicas na utilização do termo (OLIVEIRA, 2009). O final do século XIX e principalmente o século XX apresentam-se como sendo a grande época da Educação de Adultos, sendo o primeiro marco decorrente das mudanças determinadas pelos conflitos bélicos mundiais.

\footnotetext{
${ }^{3}$ FARIA, M. J. IntegrArte: um projeto comunitário com famílias refugiadas, 2018, 125f. Tese (Mestrado em Educação-EAIC. UMINHO, Braga).
} 
Assim, a partir de 1949 a ONU-UNESCO começou a promover Conferências Internacionais de Educação de Adultos (CONFINTEAS), nas quais se debateram e indicaram as grandes diretrizes e políticas globais da educação de adultos.

Centramo-nos em 1976, quando a UNESCO divulga a Recomendação de Nairobi. Nela se apresenta, de um modo explícito, a visão de educação à qual nos vinculamos, com uma enfase na educação permanente e comunitária, as suas finalidades e princípios. Fala-se pela primeira de vez de Educação ao Longo da Vida, ou seja, já não se trata apenas de alfabetizar formalmente as pessoas. "Educação de Adultos" passa a designar:

the entire body of organized educational processes, whatever the content, level and method, whether formal or otherwise, whether they prolong or replace initial education in schools, colleges and universities as well as in apprenticeship, whereby persons regarded as adult by the society to which they belong develop their abilities, enrich their knowledge improve their technical or professional qualifications or turn them in a new direction and bring about changes in their attitudes or behaviour in twofold perspective of full personal development and participation in balanced and independent social, economic and cultural development, adult education, however, must not be considered as .an entity in itself, it is a s u b-division, and an integral part of, a global scheme for life-long education and learning. (UNESCO, 1976, p. 3).

Mencionamos também a CONFINTEA VI, ocorrida em Belém, no Brasil, em 2009. O seu grande desafio consiste em passar da retórica à ação reunindo esforços para que as recomendações apresentadas sejam implementadas nas políticas públicas da educação de jovens e adultos. Nela, a aprendizagem ao longo da vida constitui "uma filosofia, um marco conceitual e um princípio organizador de todas as formas de educação, baseada em valores inclusivos, emancipatórios, humanistas e democráticos, sendo abrangente e parte integrante da visão de uma sociedade do conhecimento" (UNESCO, 2010, p. 3). Se destacou a compreensão da natureza intersetorial e integrada da educação e aprendizagem de jovens e adultos, a relevância social dos processos formais, não formais e informais e a sua contribuição fundamental para o futuro sustentável do planeta" (UNESCO, 2010, p. 4).

Decorrentes desta CONFITEA, em 2015, definem-se os 17 ODS, após reunião, em NYC, para adotar uma agenda com vista à erradicação da pobreza e ao desenvolvimento económico, social e ambiental à escala global até 2030. Deverão ser implementados por todos os países, abrangendo áreas diversas, contudo interligadas. Portugal teve uma participação importante no processo de definição da Agenda 2030, com destaque para a defesa dos objetivos de promover sociedades pacíficas e inclusivas, erradicar todas as formas de discriminação e de violência com base no gênero.

Existem diferentes tipos de paz: a paz passiva, que é simplesmente a ausência de violência ou de conflitos e a paz ativa, que se refere a aceitação e a compreensão da existência de diferentes perspectivas, a luta contra a desigualdade de gênero, a xenofobia e o racismo, a cooperação entre povos. Por último, o desenvolvimento de pensamento crítico e a responsabilidade social, motores fundamentais desta mudança indispensável e urgente a nível global, começando pela educação. Educar para a paz "tornou-se uma necessidade e um direito-dever do educador" (VISALBERGHI, 1984, p. 24). Portugal e Grécia concretizam a paz no acolhimento de migrantes e refugiados, após o fecho 
das outras nações europeias, dado se confrontarem com a violência, a degradação e a assimetria das relações humanas, a vulnerabilidade dos direitos humanos, a crise ecológica, o racismo e a xenofobia (ACNUR, 2018).

Existem organizações que defendem que o conceito de refugiado não pode ser integrado no conceito de migração. Contudo, segundo a Organização Internacional para a Migração (OIM), o conceito de refugiado e migração podem ter como base a mesma ideologia. Migração é então,

[...] o processo de atravessamento de uma fronteira internacional ou de um Estado. É um movimento populacional que compreende qualquer deslocação de pessoas, independentemente da extensão, da composição ou das causas; inclui a migração de refugiados, pessoas deslocadas, pessoas desenraizadas e migrantes económicos. (OIM, 2009, p.40).

Recorrendo à Organização das Nações Unidas "refugiados são especificamente definidos e protegidos no direito internacional. Refugiados são pessoas que estão fora de seus países de origem por fundados temores de perseguição, conflito, violência ou outras circunstâncias que perturbam seriamente a ordem pública e que, como resultado, necessitam de proteção internacional" (ACNUR, 2016, p. 1).

A migração forçada é um conceito muito semelhante ao de refugiado. As famílias que integram este projeto foram coagidas a este tipo de migração: "um movimento migratório em que existe um elemento de coação, nomeadamente ameaças à vida ou à sobrevivência, quer tenham origem em causas naturais, quer em causa provocadas pelo homem" (OIM, 2009, p.41).

Recorrendo, entre outros documentos, ao Manifesto por uma cultura de paz e não-violência (UNESCO, 2000), percebemos que a educação para a paz deve incitar a conscientização social e um reconhecimento do valor do compromisso cívico. É premente equilibrar as desigualdades de modo que se possa traçar um objetivo comum, com vista à paz global. Assim, o intuito da educação deve ser o reforço da identidade pessoal com foco em ideias e ideais que reforcem a paz, a amizade e solidariedade entre os diferentes povos e culturas. Os diversos elementos que simbolizam os povos, como a herança cultural; a forma como cuidamos do ambiente que nos rodeia; o processo de produção e o tipo de consumo que fazemos, é algo que para além de valorizado, deve ser explicado e sobretudo exemplificado e divulgado, para um maior conhecimento do que é e deve ser, o desenvolvimento sustentável. Não podemos esquecer, a harmonia necessária entre estes princípios e os valores morais, necessidades e respectivos interesses, vitais para o ser humano, presentes na Declaração Universal dos Direitos Humanos (OLIVEIRA, 2008).

[...] A cultura da paz está pautada em valores humanos que precisam ser colocados em prática, a fim de passarem do estado de intenção para o exercício da ação, transformando-se, concretamente, em atos. Tais valores, que se traduzem em éticos, morais e estéticos, nos encaminham para o despertar de expressões de amor e manifestações de respeito, que têm estado adormecidas, nos últimos tempos. (DUPRET, 2002, p. 91-92). 
O projeto IntegrArte interveio de acordo com alguns dos ODS. Assim, o principal enfoque foi a educação para a paz, a erradicação da pobreza e da fome, o acesso à saúde e à educação inclusiva e de qualidade (o ensino da língua portuguesa tornou-se uma ferramenta fundamental não só para que as famílias pudessem comunicar, mas também se integrarem na sociedade portuguesa); a promoção da igualdade de género e o incitamento ao empoderamento das mulheres. Ele foi criado com o especial intuito de ajudar e apoiar à integração das famílias refugiadas (por guerra, num caso, e por racismo, noutro), através de diversas formas de arte. O patrimônio cultural aproxima as pessoas e contribui para sociedades mais coesas, gerando crescimento e emprego. O objetivo principal do Ano Europeu do Patrimônio Cultural conjugou-se com nossos propósitos, dado defender a história e valores europeus, com um perfil aberto e multifacetado, procurando ir ao encontro de outras culturas. A Educação Artística e Cultural para os adultos, enriquece a vida de crianças e adultos, ajudando-as a pensar de forma crítica e criativa. Pode igualmente servir como uma poderosa ferramenta para a inclusão social, especialmente quando se trabalha com migrantes, minorias e outros grupos vulneráveis.

A arte e a cultura são aspectos importantes no desenvolvimento e na qualidade de vida de cada um, seja como meio de lazer, de forma passiva, seja como criação artística de forma ativa. Marques (2013) e Matarasso (1997) afirmam que projetos artísticos podem também melhorar a autoconfiança e o bem-estar dos participantes e ainda combater os estereótipos e discriminação. Quando realizados em espaços comunitários, o público tem um contacto mais próximo com a realidade das pessoas que passam por este tipo de exclusão, percebendo com mais profundidade, as lutas daqueles que sofrem múltiplas exclusões, servindo isto para que estes, vítimas de uma realidade infortuna, possam mostrar as suas preocupações, defender os seus pontos de vista e experiências.

\begin{abstract}
A arte transcende qualquer ideologia, permitindo que o que prevaleça seja, de facto, o contacto com a verdadeira essência humana. Desta forma, proporciona-nos a capacidade de nos reinventarmos, libertarmos e consequentemente reeducar-nos e reconstruir-nos. Educação pela Arte é uma metodologia que privilegia a liberdade de expressão do indivíduo para criar, inventar, experimentar, pensar, errar, desejar, sentir, questionar, criticar, transformar, para refletir sobre particularidades, semelhanças e diferenças, para explorar o lado sensível e emocional do ser, para extrair das expressões a arte, a versatilidade e a criatividade expressiva para saber argumentar, para saber mediar o seu pensamento, a sua forma de ser e de estar junto a grupos distintos no complexo processo da interação humana. (LIBÂNIO, 2013, p. 26).
\end{abstract}

A educação pela arte permite ainda que tenhamos contato ao nível dos afetos, com descobertas significativas, transversais e integradoras a todas as áreas e domínios do conhecimento, que poderão servir de ferramentas para o delinear de uma vida rica em competências para encontrar respostas aos desafios e obstáculos. É através dos nossos sentidos que conseguimos observar a arte, senti-la, tomando consciência de que podemos ser mais, ver mais, pensar mais e saborear mais. Com efeito, o empoderamento comunitário decorre do empoderamento psicológico, especialmente quando nos encontramos em países culturalmente diferentes do nosso; respeitar a diferença do outro na ajuda 
ao seu processo de empoderamento exige estarmos disponíveis para cuidar do seu bem-estar psicológico e cultural, nomeadamente via expressão artística, como esta intervenção demonstra (OLIVEIRA, 2017).

\section{METODOLOGIA EM AÇÃO}

As atividades foram planejadas e implementadas com os refugiados após sua auscultação formal (via inquérito), e informal, dos seus interesses e necessidades. Foram agrupadas em ateliers para compreensão articulada com as concepções teóricas, neles constando os métodos, técnicas, objetivos gerais (OG), e objetivos específicos (OE), enquadrados em metodologia qualitativa.

\section{Atelier da Língua Portuguesa}

OG: Valorizar práticas que potenciem o empoderamento; OE: Mobilizar capacidades de expressão e de comunicação em língua portuguesa; possibilitar o exercício de uma cidadania autônoma.

Descrição:

Foi realizado semanalmente. Na linhagem de Freire (1981), trabalhou-se o vocabulário por temas que faziam parte dos seus quotidianos, quer domésticos, quer comunitários, quer profissionais: família, casa em geral; cozinha, quarto; casa de banho, sala; rua, escola; festas, restaurante; escritório, supermercado; loja de roupa, hospital; estação de comboio, oficina; construção, aeroporto; porto, parque; animais, quinta; praia, campo; estações do ano, animais de estimação; corpo humano, profissões; desportos, circo; tempo, cores e números. Utilizamos dicionários ilustrados com imagens, nos quais as famílias liam a legenda e a discutiam. Nas imagens dos objetos que não conheciam, iam sendo explicadas as suas funções; era feita uma correção quanto à forma como se pronunciavam as palavras. Em média foram trabalhados 4 temas por semana. Tornou-se possível aplicar este método de aprendizagem do vocabulário com as duas famílias dada a sua forma lúdica. Foram ainda abordados alguns verbos (Ser, Estar, Fazer, Ter, Conhecer, Visitar) e a forma como são conjugados. Aprenderam também a saudar pessoas, a apresentarem-se, a utilizarem adjetivos e ainda a forma de se expressar e em certos serviços administrativos portugueses (escola, SEF, Segurança Social, correios, eletricidade, etc).

Relativamente às crianças com 2 e 6 anos, a língua portuguesa foi sendo ensinada de forma diferente, com jogos de um alfabeto analógico, bem como com alguns jogos de tabuleiro. Durante o ano, realizou-se uma recolha de brinquedos e jogos para que as crianças pudessem aprender a língua através da brincadeira. Com a criança de 6 anos, a pintura e a criação de histórias através do desenho e da sua imaginação, foram também impulsionadores para desenvolver a sua criatividade e expressão oral. Realizávamos intermitentemente o jogo do STOP, pois era divertido e incitava a capacidade de procurar novas palavras ou palavras menos utilizadas.

\section{Atelier de Artes Plásticas}


OG: Desenvolver a sensibilidade artística. OE: Fomentar o desenvolvimento da expressão através das artes plásticas.

Descrição:

Foi dividido em dois módulos: a atividade de Natal e atividade da criação do portfólio. Na primeira elaborámos uma coroa de Natal de cartolina com a forma das mãos de cada participante, em forma de círculo e colamos. As coroas foram utilizadas por cada família para decorar as suas casas. Decoramos também pinhas através da recuperação de materiais e recursos como rolos de papel higiênico, cartolinas e palitos. Começou-se por pintar as pinhas com spray de tinta dourada e prateada; em seguida recortou-se rolos de papel higiênico para fazer o efeito de tronco. Por fim, desenharam-se estrelas em cartolina, sendo que no final as estrelas foram coladas em palitos para criar o efeito do topo de uma árvore de Natal. A atividade proporcionou momentos de alegria, partilha de ideias, ajudando a desenvolver a criatividade, concentração e coordenação.

O portfólio de cada família foi construído pelos seus membros, decorado e legendado (em português e na língua nativa de cada família), contendo fotos de todas as atividades.

\section{Atelier de Jogos}

OG: Estimular o desenvolvimento pessoal e social; OE: promoção da integração. Descrição:

Consistiu em dois grupos de atividades: a participação no projeto Integration Game, e as atividades de jogos elaboradas nas férias da Páscoa. Integration Game, um jogo de tabuleiro, em parceria com a Associação Cidade Curiosa de Braga, que assumiu um papel preponderante na integração das famílias refugiadas, a nível cultural. Jogos como "Caravelas4" e "Aljubarrota5" tiveram um forte impacto nas famílias, com a nossa explicação dos Descobrimentos dos portugueses e do Tratado de Zamora. Jogos infantis como "Spaghetti6" e "Passa o desenho7", tiveram um forte impacto nas crianças ajudando a desenvolver a concentração, coordenação e motricidade fina.

\section{Brincar com a tradição}

Esta atividade realizou-se em quatro sessões nas férias da Páscoa numa instituição local. As crianças interagiram com outras crianças refugiadas e portuguesas (incluindo algumas com deficiência mental).

A primeira sessão iniciou-se com uma apresentação de todos os participantes. O primeiro jogo foi a corrida dos sacos, seguida do jogo de equilibrar a bola e por último foram feitas pelas crianças, bolas de sabão gigante com material utilizado por malabaristas profissionais.

Iniciamos a segunda sessão com o jogo das sombras chinesas. Numa sala com ambiente escuro, um pano branco aberto com um foco de luz atrás, cada criança tirava de um saco um papel com uma figura que teria de imitar sem produzir qualquer som, e as outras crianças adivinhavam a que se referia. Jogamos também um bowling temático, com um conjunto de questões e tarefas relacionadas a cada tema, redigidas em pequenos cartões enrolados. A cada uma dessas perguntas 
ou tarefas foi atribuída uma pontuação de acordo com o seu grau de dificuldade. Utilizamos garrafas plásticas de litro e meio, uniformes e vazias para fazer os pinos, tendo nelas sido colocados os cartões. Foi jogado em português e em inglês.

Na terceira sessão jogamos foto-mímica, jogo da estátua, jogos musicais e por fim, o jogo da cadeira. Todos cantaram e dançaram, com música ao vivo - e coreografia - a nosso cargo, juntamente com uma guitarra temas infantis tradicionais portugueses. Foi ainda realizado o jogo das notas musicais, utilizando o desenho da macaca. Cada quadrado do jogo da macaca retratado de 1 a 8 , representava uma nota musical, de Dó grave ao Dó agudo.

$\mathrm{Na}$ quarta de "brincar com a tradição" realizamos atividades que decorreram de forma ligeiramente diferente. $\mathrm{O}$ objetivo dessa sessão passou por fazer um pequeno lanche e confeccionar com as crianças um bolo de iogurte para que aprendessem uma nova receita. A sessão terminou com o jogo do dominó com cartas temáticas e com a construção de um castelo com blocos de legos. Depois de ser confeccionado o bolo de iogurte (e enquanto ele cozia), as crianças até aos 6 anos jogaram o jogo do dominó "Gombby", com cartas temáticas. As crianças a partir dos 6 anos construíram um castelo através do jogo "Castillos", um jogo espanhol com mais de 100 peças. No final lanchou-se o bolo por eles confeccionado.

\section{Atelier Musical}

OG: Educar para a Paz. OE: proporcionar a autoconfiança e integração.

Descrição:

Consistiu em ouvir músicas dos 3 países de forma a partilhar e conhecer estilos musicais de cada nacionalidade. Nessa atividade foi notório o gosto da ucraniana por uma música do seu país, da sua banda favorita (ОкеанЕльзи). Com uma guitarra e com a voz da ucraniana, a música foi interpretada e ensaiada. No entanto, o objetivo da atividade era também trabalhar uma música, acrescentando algo. Assim, fez-se a letra para essa mesma música em 3 línguas: português, bangladeshiano e ucraniano. Primeiramente foi escolhido um tema para redigir a letra da música. A paz e a luta por um mundo melhor, foram os temas escolhidos. Fizeram o refrão, que foi escrito em português e modificado de forma a encaixar na melodia e ritmo da música original. As estrofes foram escritas pela mulher em ucraniano e de acordo com o sentido do refrão. Para a construção das estrofes foi feito um pequeno exercício de palavras para a letra ganhar mais cor e diversidade a nível de vocabulário. O último refrão, chamado o refrão forte, foi elaborado pelo marido em bangladeshiano.

\section{Atelier de Danças Circulares}

OG: Estimular o desenvolvimento pessoal e social; Desenvolver a sensibilidade artística. OE: Proporcionar a autoconfiança e a conexão em grupo por danças circulares.

Descrição: 
O foco esteve em músicas e danças de diversas partes do mundo e de vários gêneros musicais, apresentando possibilidades afetivas, subjetivas e educativas de construção de uma cultura da paz, na qual os corpos em movimento se tocam e se confraternizam, repensando e reposicionando formas de sociabilidades e de práticas culturais na contemporaneidade. As danças circulares desenvolvem ainda a conexão, partilha, alegria e concentração. Assim sendo, semanalmente foram dançadas e coreografadas danças típicas de diversos países como Brasil, Portugal, Curdistão, Congo, Ucrânia, etc.

Continua a acontecer semanalmente, gratuito para refugiados/migrantes, e uma destas famílias (4 pessoas) continua a fazê-la.

Tem sido utilizada, a pedido, para animação de instituições que acolhem refugiados de vários tipos, além de outras instituições de educação não formal de adultos e de integração intergeracional (escolas, lares de idosos, centros sociais, empresas).

\section{Atelier Gastronômico}

OG: Valorizar práticas que potenciem o empoderamento e a integração. OE: Incitar uma maior proximidade com a sociedade portuguesa; Conhecer as culturas e as tradições dos países da população alvo, e portuguesas.

Descrição:

Ocorreu em quatro atividades.

Em duas delas organizou-se um lanche natalício com doces típicos portugueses. A mulher ucraniana seguiu a receita de leite-creme, explicando que não era comum fazerem-se sobremesas com esta textura e sabor no seu país. Foi-lhe oferecido por nós bolo-rei e explicada a sua importância em Portugal. Durante a degustação da comida, ela foi conversando sobre quando e como se vive o Natal na igreja ortodoxa; foram cantadas algumas músicas de Natal em português, bem como músicas alusivas ao dia de reis. As músicas permitiram que a mulher se familiarizasse com músicas portuguesas, assim como praticasse o português. A família congolesa cozinhou aletria.

A terceira atividade gastronômica teve como base a sopa do Bangladesh, com uma textura muito diferente da portuguesa.

A quarta atividade gastronômica foi um prato típico congolês mais especificamente Kizaka, feita com Mandioca (pé de Mandioca no Brasil), acompanhada por bacalhau frito e arroz. O prato acabou por ter características gastronômicas dos dois países.

\section{Atelier do Lar}

OG: Valorizar práticas que potenciem o empoderamento; OE: Sensibilizar para o exercício da cidadania autônoma.

Descrição:

Foi realizado apenas com a família congolesa. Com as primeiras visitas e intervenções, foi detectada uma grande desorganização na residência desta família, especialmente nos quartos. Este 
atelier surgiu não só para ajudar a melhorar a qualidade de vida e saúde desta família, como também prevenir situações desagradáveis com a segurança social e senhorio.

Inicialmente, nos quartos das crianças, a situação era complicada: roupas, utensílios e brinquedos, misturados nos armários e estantes por todo o quarto. Perante esta situação, a intervenção passou por estabelecer (juntamente com as crianças) que cada uma teria uma estante e uma gaveta para colocar a sua roupa. Começou-se a agrupar do lado direito da estante todas as camisas, camisetas, e do lado esquerdo, calças e calções; na última estante todo o calçado. Na cômoda cada criança teria também uma gaveta onde poderia colocar toda a roupa interior (íntima) e pijamas.

Os brinquedos passaram para a sala que posteriormente também sofreu alterações ao nível da arrumação e organização. Esta atividade de organização do quarto foi bem-sucedida e compreendida pelas crianças, pois no fim da atividade mostraram-se muito felizes e satisfeitas por terem o quarto arrumado e organizado. Relativamente ao quarto da mãe, não sofreu qualquer alteração devido ao fato de se encontrar mais arrumado do que o dos filhos e também por não ter demonstrado vontade de se organizar melhor. Foi então respeitado o espaço, vontade e privacidade da mesma.

A sala também se encontrava mal distribuída e que foi reorganizada pela família com nossa ajuda.

\section{Atelier de Estética}

OG: Valorizar práticas que potenciem o empoderamento. OE: Despertar uma maior autoconfiança e autoestima.

Descrição:

Realizou-se apenas com a mulher congolesa pois foi uma das necessidades detectadas no diagnóstico, a maquiagem de dia. Iniciou-se com a apresentação do material, o nome dos produtos, as suas funções e a melhor forma de os aplicar. Foram também abordadas a importância de conhecer os tipos de pele, algumas dicas sobre maquiagem de noite e maquiagem de noivas. Depois, foi maquiada uma voluntária para que a mulher pudesse desta forma aprender. Depois, a mulher aplicou na mestranda o que aprendeu, elaborando a maquiagem de dia.

\section{Atelier de Visitas Guiadas}

OG: Estimular o desenvolvimento pessoal e social; valorizar práticas que potenciem o empoderamento; desenvolver a sensibilidade artística. OE: Promover o intercâmbio entre línguas e culturas; mobilizar capacidades de expressão e comunicação em língua portuguesa; sensibilizar para o exercício da cidadania autônoma; incitar a uma maior proximidade com portugueses; dar a conhecer a cultura e as tradições portuguesas e das culturas dos países da população-alvo.

Descrição:

Foram feitas 3 visitas: a Guimarães, Porto e Braga, com a possibilidade de as famílias conhecerem a diversidade a nível cultural, histórico e paisagístico.

Visita a Guimarães: 
Juntaram-se várias famílias de refugiados: duas famílias da Síria e a família do Congo. Contamos com a colaboração de outros voluntários que trabalhavam com as outras famílias de refugiados e o plano foi construído com todos os implicados (24 pessoas).

A família da Ucrânia não pôde comparecer pois a mulher tinha acabado de ser mãe. Iniciou-se a visita de ônibus às 9h30. A primeira parada foi no Paço dos Duques de Bragança pela importância que tem na História de Portugal. A nível arquitetônico é também muito rico e belo. As famílias ficaram surpreendidas e encantadas. Depois, fomos ao Castelo de Guimarães, passeamos por Guimarães, focando-nos na questão patrimonial. De tarde, o percurso para o Monte da Penha foi por teleférico. Após a chegada, as famílias fizeram uma visita pedonal ao Monte, contemplaram vistas extraordinárias da cidade, assim como usufruíram de toda a natureza. Foram registadas muitas fotografias e a descida procedeu-se também de teleférico. O regresso deu-se ao fim da tarde, de ônibus.

Visita ao Porto:

De manhã, partimos até à Estação de trem de São Bento, no Porto. O primeiro local a ser visitado foi o Palácio da Bolsa, que foi feita por uma guia, em português. As famílias foram compreendendo com a ajuda sobretudo das crianças de uma família síria que compreendiam português, usando o árabe para a tradução. Dado serem todos islâmicos, o árabe básico serve como língua franca entre todos eles. Depois, fizemos uma visita ao Museu das Marionetes, oportunidade para recriar e imaginar diferentes histórias e cenários.

Durante o almoço (num parque perto da Torre dos Clérigos), fomos em direção à livraria Lello, que se encontrava literalmente repleta de visitantes e optámos pela zona da Ribeira onde foram tiradas algumas fotografias. Para ficarmos abrigados da chuva, antecipamos a visita à Casa do Infante, um museu e um dos edifícios mais antigos da cidade. O guia explicou-nos de forma genérica algumas curiosidades acerca do museu e das suas funcionalidades da sua construção. A meio da tarde, ao dirigirmo-nos para a estação de trem de São Bento, de regresso. № de participantes: 21 (várias famílias de migrantes e refugiados da zona geográfica onde se realizou o projeto e voluntários).

Visita a Braga:

Visitou-se Braga com a usual junção de famílias e de voluntários da mesma zona geográfica do projeto. A visita à Braga foi programada de maneira a visitarmos de manhã o Bom Jesus e na parte da tarde, o centro da cidade (Museu da Imagem, Museu do Traje, Largo do Paço, Reitoria, Jardim de Santa Bárbara e Museu dos Biscainhos) através do free walking tours, que são passeios guiados, usualmente de cunho turístico e realizados a pé, que ocorrem de maneira sistemática em diversas cidades do mundo.

De manhã, iniciamos a visita ao Bom Jesus através do elevador do Bom Jesus, percurso que adoraram fazer. O elevador foi o primeiro funicular construído na Península lbérica e é o mais antigo em serviço a utilizar o sistema de contrapeso de água. A interação entre os vários elementos da população-alvo, nomeadamente, com população portuguesa e entre si, proporcionou elementos de lazer e de grande alegria e descanso, sobretudo para as crianças mas também para algumas pessoas que se encontravam a cumprir os preceitos do Ramadão: Estava muito calor e a população-alvo preferiu ficar naquele local aprazível, com acesso a água e sombra, partilhando as suas comidas, convivendo, do que seguir para o estio intenso e seco que caracteriza o calor na cidade em questão. 


\section{Atelier de Convívio}

OG: Estimular o desenvolvimento pessoal e social; potenciar o empoderamento. OE: Promover o intercâmbio entre linguagens e culturas; Mobilizar capacidades de expressão e comunicação em língua portuguesa; conhecer a cultura, tradições portuguesas e as culturas dos países da população-alvo. Descrição:

Programação e elaboração de almoços de convívio entre voluntários e famílias de refugiados com o objetivo de elaborar trocas gastronômicas entre países assim como um maior convívio entre famílias e culturas de forma a poderem criar laços e partilharem aquilo que pretendiam partilhar.

Este atelier dividiu-se em duas atividades: a participação no projeto "Família do lado" organizado pelo ACM (Alto Comissariado para as Migrações) e o "Almoço entre PAR'es" promovido pela PAR (Plataforma de Apoio aos Refugiados).

A primeira atividade, "Família do Lado", é uma iniciativa que consiste no acolhimento de uma família-imigrante ou refugiada e outra autóctone (natural do país) e vice-versa, para a realização de um almoço-convívio, típico da sua cultura, como forma de acolhimento do "Outro". O objetivo passa por contribuir para uma integração mais efetiva dos imigrantes em Portugal, reforçando assim as relações sociais e a diversidade cultural. O projeto transnacional foi criado na República Checa em 2004 e assenta no conceito de "Bairros Inclusivos". Todos os encontros acontecem no domingo, dia 26 de novembro, às $13 \mathrm{~h} 00$, em todo o território nacional, Espanha e República Checa. O almoço decorreu em uma ONG que aderiu ao programa da ACM, com a troca de gastronomia entre vários países, entre eles Angola, Congo, Ucrânia, Síria, Palestina, Mauritânia, etc. Após o almoço, as famílias participaram das danças circulares, com músicas portuguesas, inclusive a "Canção do Mar" da fadista Amália Rodrigues, cuja coreografia foi elaborada por uma das autoras deste artigo e dedicada à temática dos refugiados. Os cidadãos do Congo e do Curdistão impressionaram os presentes com as danças típicas dos seus países. Ao longo desse último mês, semanalmente foram feitos ensaios (ao domicílio e no atelier das danças circulares) para preparar algumas danças circulares, mais especificamente das músicas "Canção do Mar", "Zungueira" e de danças típicas do Curdistão, no que respeita ao público-alvo deste projeto.

A segunda atividade, realizou-se meses a seguir, também em uma ONG em parceria com uma instituição local com ligações à PAR.

O "Almoço entre PAR'es" foi um encontro de famílias e voluntários, desta vez atingindo outras dimensões pois surgiram famílias acolhidas em diversas cidades do norte de Portugal, acolhidas por vários organismos nacionais e internacionais.

Cada família trouxe um prato típico do seu país e o sentimento de partilha entre as famílias e voluntários fez-se notar. O almoço-convívio prolongou-se pela tarde, com algumas atividades, algumas da responsabilidade da ONG.

O nosso contributo manifestou-se sobretudo na parte de tarde contando inclusive com a presença da Literatuna, Tuna de Letras da Universidade do Minho (à qual uma das autoras deste artigo pertencia), alegrando o convívio, e divulgando um pouco da cultura acadêmica e música tradicional 
portuguesa, através de músicas provenientes dos Açores como o "Pézinho da Vila" e do Minho, "Vira do Minho" que foram dançados por voluntários e algumas famílias. Nº de participantes: 7 (famílias do Congo e Ucrânia).

\section{AVALIAÇÃO E DISCUSSÃO DE DADOS}

Neste projeto, a avaliação realizou-se em três momentos, a fase do diagnóstico de necessidades, a fase da implementação de atividades (avaliação contínua) e a fase da avaliação (avaliação final). Em cada momento da avaliação, foram utilizados diferentes instrumentos, por vezes em simultâneo, de modo a tornar a intervenção mais viável. Na fase da avaliação diagnóstica, procurou-se conhecer o público-alvo, os seus interesses e necessidades. Para a concretização desse diagnóstico, foram utilizados métodos e técnicas, como inquéritos por questionário, entrevista semiestruturada, observação participante e conversas informais. No que concerne à avaliação contínua, esta realizou-se ao longo de todo o projeto através da observação e de um diário de bordo, com registro de todas as ocorrências, do empenho do público-alvo no decorrer de cada atividade.

Os inquéritos de satisfação passados ao público-alvo no fim de cada atividade, em que se pretendia compreender a utilidade das atividades, assim como, o seu grau de satisfação, revelou ser um importante instrumento de avaliação no decorrer do projeto. Por fim, a avaliação final que neste projeto foi realizado através de uma pequena atividade que consistiu na elaboração de um pequeno portfólio, "portfólio das memórias", onde foram anexadas todas as fotografias tiradas com as famílias ao longo de todo o projeto. No portfólio as famílias legendaram foto a foto, na sua língua nativa e em português. Ao longo da atividade as famílias foram recordando os momentos vividos, o que gostaram ou não gostaram, o que aprenderam e o que significou para elas a participação no projeto.

A análise crítica e capacidade de reflexão são tarefas indispensáveis em qualquer projeto, durante as diferentes fases da sua aplicação/realização. Assim, apresentamos agora a nossa reflexão de todo o trabalho realizado, centrado na análise crítica dos resultados (obtidos por inquéritos semiabertos anônimos, realizados no final de cada atelier, bem como de conversas informais).

Analisando de um modo transversal todo o projeto: sendo um projeto de intervenção comunitária possui características diferenciadas de outros projetos de educação de adultos, em Portugal. Primeiramente, o público-alvo deste projeto provinha de três países diferentes, com línguas, religiões e culturas distintas. Detectando, no diagnóstico de necessidades, a imensa vontade do público em aprender a língua portuguesa, este atelier teve de fato um grande impacto e resultados muito positivos. No final do projeto, estas famílias já tinham a capacidade de comunicar e escrever em português de forma mais correta e acima de tudo com mais confiança. Estes resultados demonstram o poder que a língua e a capacidade de comunicar têm no quotidiano e na vida das pessoas (FREIRE, 1981).

Este projeto teve como grande preocupação, além da inclusão das famílias refugiadas, fornecer-lhes ferramentas de empoderamento, para uma educação permanente ao longo das suas vidas. O atelier de estética, implementado essencialmente com a família do Congo foi um pequeno, mas enorme, passo, pois esta ganhou mais confiança, gosto pela área e mais noções da mesma. Num 
futuro próximo, quem sabe se esta poderá ingressar num curso de formação nessa área e consequentemente ter emprego nesta área.

As visitas guiadas e o atelier do convívio, tiveram, igualmente, a mesma importância e impacto nas famílias. O contacto com novas pessoas, espaços, arquiteturas, culturas e serviços, despertaram um maior conhecimento e abertura quanto a Portugal, sentindo-se mais incluídos e permitindo-lhes desenvolver a capacidade de comunicar em português, de utilizar serviços (transportes públicos, museus, bibliotecas, restaurantes). Por fim, tudo o que envolveu a arte no decorrer deste projeto, revelou-se uma poderosa ferramenta que estimulou a capacidade de exteriorizar as mais diversas emoções, sentimentos e pensamentos de uma forma bela e simples. Por meio da música, dança e expressão plástica, estas famílias sentiram-se realmente bem-vindas e acolhidas no nosso Portugal.

\section{CONSIDERAÇÕES FINAIS}

A realização deste projeto teve profundos impactos pessoais nas suas autoras. Sentimos grande ansiedade e receio face a um público-alvo pertencente a nacionalidades, culturas e religiões diferentes. No entanto, paralelamente, consideramos que seria um dos maiores desafios que teríamos na nossa vida, a nível pessoal e profissional. A parte emocional foi, muitas vezes, de gestão complicada.

A situação das famílias, toda a sua história, percursos, obstáculos que ultrapassaram e ainda têm de ultrapassar, criaram em nós ainda mais responsabilidade e vontade de ajudar. Este projeto permitiu-nos compreender e crescer imenso ao nível cultural no que respeita a tradições, costumes, gastronomia e modos de viver das diferentes nacionalidades com as quais contactamos. Também a nível da língua, da religião e das questões geopolíticas que acontecem nestes países em questão, fizeram-nos compreender melhor, acompanhar de perto e dar assistência a quem viveu, e vivencia, esta realidade.

Ao longo do projeto foram notáveis os laços afetivos desenvolvidos com as famílias, o acompanhamento diário prestado, trabalhando dentro do seu espaço familiar, o que Ihes trazia alguma tranquilidade. Com a participação e dedicação do nosso tempo ao fim de semana, com as visitas guiadas e os almoços de convívios com outras famílias, tomamos a iniciativa de recolher alimentos e brinquedos, em parceria com entidades comerciais da zona norte do país, que doaram roupas, brinquedos e carrinhos de bebé, jogos didáticos e de tabuleiro. A nível alimentar, através de um colega, animador de uma Associação de Braga cujos alimentos aproximados do prazo de validade seriam jogados no lixo, quase mensalmente foram oferecidos enlatados, bolachas, cereais que fazia alguma diferença no orçamento mensal das famílias. Vivemos ao longo deste projeto, momentos de grande alegria, compaixão, tristeza, mas também de profunda gratidão às pessoas extraordinárias que demonstraram bondade, solidariedade na ajuda aos seus próximos, sem sequer os conhecerem.

À altura de realização deste projeto, não existiam divulgados academicamente, em Portugal, projetos não-formais com pessoas refugiadas na área de educação de adultos e intervenção comunitária. Foi por nós constada continuamente, também, a carência de intervenção especializada desta área. Não somente a assistência básica que concede alojamento, alimentação, serviço de saúde 
e educação escolar se revela ser imprescindível; é fulcral incluir, promover o empoderamento, estimular e desenvolver integralmente as capacidades desta população. Na pele de educadoras não formais (e até informais) junto deste público-alvo, consideramos que temos o dever de procurar constantemente novas vias, fórmulas e vocabulários. De fato, este público precisa de mais profissionais de educação de adultos que insistam, como nos diz Lima (2007, p. 36) "[...] na revalorização ética da vida ao longo da educação, da formação e da aprendizagem por referência a um conceito de aprendizagem socialmente responsável e sustentável".

\section{REFERÊNCIAS}

1. ACNUR. 'Refugiados'e 'Migrantes': Perguntas frequentes, 2016. Disponível em: <https://www.acnur.org/portugues/2016/03/22/refugiados-e-migrantes-perguntas-frequentes/>. Acesso em: outubro de 2019.

2. ACNUR. Refugiados, 2018. Disponível em: <https://www.acnur.org/portugues/quemajudamos/refugiados/>. Acesso em: outubro de 2019.

3. ANGER-EGG, E. Metodologia y Pratica de la Animación sociocultural. Madrid: Ed. CC, 2002.

4. $\quad$ BARROS, R. Educação de adultos. Lisboa: Piaget, 2013.

5. CANÁRIO, R. Educação de adultos: um campo e uma problemática. Lisboa: Educa, 2000.

6. DUPRET, L. Cultura de paz e ações sócio-educativas: desafios para a escola contemporânea. Psicol. Esc. Educ. (Impr.). Campinas, v. 6, n. 1, p. 91-96, June 2002.

7. FREIRE, P. A importância do ato de ler. S. Paulo: Cortez. 1981.

8. GUERRA, I. Fundamentos e Processos de uma Sociologia da ação. Cascais: Principia, 2000.

9. LIBÂNIO, M. Educação pela Arte: uma experiência para dar sentido aos sentidos. Lisboa: UNL, 2013.

10. LIMA, L. Educação ao longo da vida: entre a mão direita e a mão esquerda de Miró. S. Paulo: Cortez, 2007. 
11. MARQUES, E. Intervenção Comunitária através da Arte com pessoas em situação de sem- abrigo. Revista Espacios Transnacionales Projeto RELETRAN, No. 2. Julio-Diciembre 2013. Disponível em: http:// www.espaciost.org/experiencias-comunitarias/semabrigo/. Acesso em: outubro de 2019.

12. MATARASSO, F. Use Or Ornament? The Social Impact of Participation in the Arts. London:Comedia, 1997.

13. OIM. Glossário sobre a Migração. Direito Internacional sobre Migração, $n^{\circ} 2$ 2, 2009. Disponível em: <https://publications.iom.int/system/files/pdf/iml22.pdf>. Acesso em: outubro de 2019.

14. OLIVEIRA, C. C. Educação para a paz: Contributos das Humanidades aliadas à educação não formal e informal. In: SOARES. E., TEIXEIRA, L. (Orgs.). Práticas educativas e Cultura de Paz: articulando saberes e fazeres. Caxias do Sul: Educs, 2017.

15. OLIVEIRA, C. C. A Educação como processo auto-organizativo. Lisboa: I. Piaget, 1999.

16. UNESCO. Marco de Ação de Belém. Aproveitando o poder e o potencial da aprendizagem e educação de adultos para um futuro viável, 2010. Disponível em: <http://unesdoc.unesco.org/images/0018/001877/187787por.pdf>. Acesso em: outubro de 2019.

17. UNESCO. Manifesto 2000. Por uma cultura de paz e não-violência. Paris: UNESCO, 2000.

18. UNESCO. Recommendation on the development of adult education. Nairobi, UNESCO: 1976.

19. VISALBERGHI, A. Scuola e cultura di pace., Florencia: La Nuova Italia, 1985.

\section{Maria João Faria}

Mestre em Educação de Adultos e Intervenção Comunitária- UMINHO, Portugal.

\section{Clara Costa Oliveira}

Professora Associada com agregação.

Como citar este documento:

FARIA, Maria João; OLIVEIRA, Clara Costa. Integração não-formal de migrantes e refugiados em Portugal - Projeto Integrararte. Reflexão e Ação, Santa Cruz do Sul, v. 28, n. 3, p. 5-21, ago. 2020. 
ISSN 1982-9949. Disponível em: <https://online.unisc.br/seer/index.php/reflex/article/view/14368>. Acesso em: doi:https://doi.org/10.17058/rea.v28i3.14368. 